\title{
Effect of Quenching and Partitioning Heat Treatment on Ductile Cast Irons
}

\author{
Pipeng ZHAO ${ }^{1, \mathrm{a}}$, Jing $\mathrm{WANG}^{2, \mathrm{~b}}$, Baoxu $\mathrm{HANG}^{1, \mathrm{c}}$, Yanghe $\mathrm{WANG}^{1, \mathrm{~d}}$, Jie MA $\mathrm{MA}^{1, \mathrm{e}}$, \\ Xingchuan $\mathrm{ZHAO}^{1, \mathrm{f}}$ and Changzheng $\mathrm{WANG}^{1, \mathrm{~g}}$ \\ ${ }^{1}$ School of Materials Science and Engineering, Liaocheng University, Liaocheng 252000, Shandong, \\ China \\ ${ }^{2}$ Naval Aviation Institute, Hu Ludao 125001, Liaoning, China \\ a1071288167@qq.com, ${ }^{\mathrm{b}}$ wangjing112689@126.com, ${ }^{\mathrm{c}}$ huangbaoxu@1cu.edu.cn, \\ d985981798@qq.com, ${ }^{\mathrm{e}}$ majie@1cu.edu.cn, ${ }^{\mathrm{f}}$ zhaoxingchuan@1cu.edu.cn, ${ }^{\mathrm{g}}$ Corresponding author: \\ wangchangzheng@1cu.edu.cn
}

\begin{abstract}
In this study, the ductile cast irons were prepared by the melting process and then carried out the quenching and partitioning heat treatment. The microstructures were observed by both an optical microscopy and a field emission scanning electron microscope and the tensile strengths were measured by a uniaxial tensile tester. The effect of partitioning time on the microstructures and the tensile strength were investigated. The results showed that the matrix of as-cast samples contain about $26 \%$ ferrite and $74 \%$ pearlite and the microstructure quenched without partitioning consisted of a mixture of graphite nodules plus lath martensite plus retained austenite. With the increase of the partitioning time, the retained austenite became stable and could transform into lower bainite or carbide gradually, which gave rise to the fact that the tensile strength changed nonlinearly and reached a maximum at the partitioning time about 120 minutes. Keywords: Quenching and Partitioning, Ductile Cast Irons, Microstructure, Tensile Strength, Partitioning Times
\end{abstract}

\section{Introduction}

Because of its good casting performance, low fabrication cost, excellent mechanical properties, superior corrosion resistance and abrasive resistance [1-4], ductile cast irons (DCIs) are widely used in most areas such as auto industry, mining industry, wind turbine generator, and so on [5-6]. It is well known that the excellent properties of DCIs are determined by its microstructure which consists of a steel-like matrix and graphite nodules embedded in steel-like matrix [7-8]. Therefore, besides graphite nodules, the matrix of DCIs plays an important role in the excellent properties, especially in the mechanical properties including strength, elongation, impact toughness and hardness. Thus, in order to acquire the good matching mechanical properties, it is essential to change the matrix microstructure of DCIs by various methods. Since the matrix of DCIs has similar chemical composition and microstructure to the steels, some methods of heat treatment methods used in the steels can 
also be used in DCIs to change its matrix microstructure and then its properties. So far, the properties of DCIs have already improved by several heat treatment methods used in the steel, such as electropulsing annealing [9], quenching and tempering [10], thermomechanically treatment [11], austempering [12-13], and quenching and partitioning [14]. Among them, quenching and partitioning process is an important heat treatment method for steel and has already been discussed in details [15]. However, so far there are only few reports on the use of quenching and partitioning method to the DCIs. As a result, there are still some puzzles for DCIs under the quenching and partitioning process. For example, the carbon atoms is how to diffuse and the phase evolution process is how to carry out during the quenching and partitioning process for DCIs. Thus the main objective of this paper is to obtain knowledge about the behavior of DCIs and to have a better understand of the phase evolution of the microstructure in quenching and partitioning process. Moreover, the major contribution by applying this route is to develop a class of heat-treated DCIs, which can be a technological alternative in application of DCIs.

\section{Experimental Procedures}

The DCIs were produced by the melting process in an induction furnace with a holding capacity of $30 \mathrm{~kg}$ of molten metal. The pig iron, steel scrap, recarburizing agent, pure copper, $\mathrm{SiFe}$, and $\mathrm{MnFe}$ weighted according to the designed composition were put into induction furnace in turn. When the temperature of molten metal reached $1550^{\circ} \mathrm{C}$, RE-Mg-Si-Fe nodulizer alloy was put into induction furnace for 1.5 minutes. And then the molten metal was poured into sand molds to produce $\mathrm{Y}$ block at $1410{ }^{\circ} \mathrm{C}$. The final chemical composition was examined by direct-reading spectrometer, which is about $3.72 \% \mathrm{C}, 2.34 \% \mathrm{Si}, 0.27 \% \mathrm{Mn}$, $0.68 \% \mathrm{Cu}, 0.015 \% \mathrm{~S}$, and $0.015 \% \mathrm{P}$, with the balance of $\mathrm{Fe}$. All the samples were cut at the bottom of Y block. The samples were austenitized at $900^{\circ} \mathrm{C}$ for 2 hours [14] and then quenched into cylinder oil at $160^{\circ} \mathrm{C}$ for 2 minutes. After that, the specimens were quickly poured into nitrate furnace with $300^{\circ} \mathrm{C}$ to carry out partitioning process. The partitioning times kept 10, 30, 60, 120, and 180 minutes, respectively. The mechanical properties were measured by the uniaxial tensile tester and the microstructures were observed by both an optical microscopy (Axio Scope A1, Zeiss Company, Germany) and a field emission scanning electron microscope (FESEM, Merlin Compact, Zeiss Company, Germany).

\section{Results and Discussions}

Fig. 1 (a) shows the microstructure of unetched as-cast samples. It is clear that there are about 280 graphite nodules in $1 \mathrm{~mm}^{2}$ matrix and all the graphite nodules, whose size is smaller than $40 \mu \mathrm{m}$, dispersed uniformly in the matrix. In addition, most graphite nodules display spherical shape and the nodularity is above $90 \%$, indicating the graphite nodules are rated for 3 grade of nodulization in accordance with the ASTM standard A247 [16]. After etching, the microstructure with ferritic and pearlitic matrix appears through observation of the optical microscope, as shown in Fig. (b) 


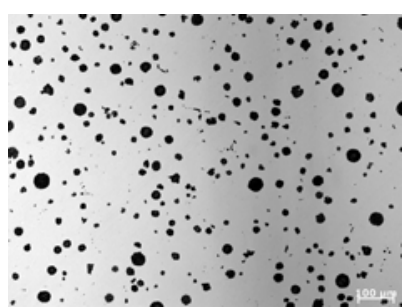

(a)

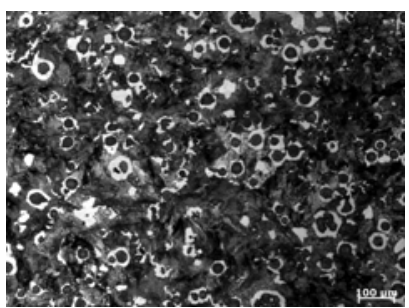

(b)

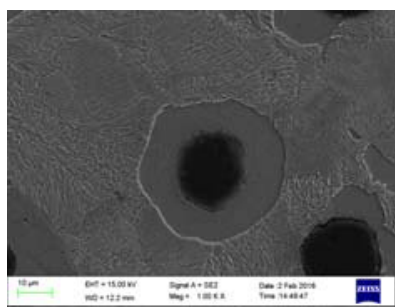

(c)

Figure1. (a) Microstructure of unetched as-cast DCIs; (b) Microstructure of etched ascast DCIs; (c) Microstructure of etched as-cast DCIs (FESEM microscopy)

It can be estimated by the software attached by Axio Scope A1 that the matrix contains about $26 \%$ ferrite and $74 \%$ pearlite. Most of ferrites surround the graphite nodules and form the shape with bull's eye. The pearlite is composed of alternating lamellar ferrite and cementite and the interlamellar spacing is about 0.2-1 $\mu \mathrm{m}$, as shown in Fig.3 (c). Assuming that the graphite nodules only contain carbon atoms and all the alloying elements distribute in the matrix, which has already confirmed by our EDX analysis, the approximate chemical composition of matrix can be estimated by removing the content of graphite nodules from the whole area, which is about $0.55 \% \mathrm{C}, 2.72 \% \mathrm{Si}, 0.32 \% \mathrm{Mn}, 0.72 \% \mathrm{Cu}, 0.018 \% \mathrm{~S}$, and $0.018 \% \mathrm{P}$, with the balance of Fe.

Thus, it can be estimated the $M_{s}$ temperature by applying Andrew's linear equation [17].

$$
M_{s}\left({ }^{\circ} \mathrm{C}\right)=539-423 \mathrm{C}-30.4 \mathrm{Mn}-7.5 \mathrm{Si}+30 \mathrm{Al}
$$

The calculated result shows that the $M_{s}$ is about $277.8^{\circ} \mathrm{C}$ and then the selected temperature for quenching $\left(T_{q}\right)$ is about $160^{\circ} \mathrm{C}$. According to Koistinen and Marburger equation [17]:

$$
1-V_{\alpha}=\exp \left\{-\beta\left(M_{s}-T_{q}\right)\right\}
$$

where $V_{\alpha}$ stands for the percentage of austenite transformed into martensite, $\beta=0.011$. The calculated result gives a value of $V_{\alpha}=0.73$. That is to say there is about $73 \%$ austenite transformed into martensite and the amount of retained austenite is about $27 \%$, which is confirmed by the microstructures of etched samples only quenched at $160^{\circ} \mathrm{C}$, as shown in Fig. 2.

Fig.2 indicates obviously that the microstructure is composed of a mixture of graphite nodules plus lath martensite with high carbon plus retained austenite. Through the software attached by Axio Scope A1 it can be obtained that the content ratio of martensite and retained austenite is about 75: 25, which is in agreement with the result calculated above. Among the lath martensite, there exist lots of dislocations and dislocation tangles, which can decrease the mechanical properties of samples. Meanwhile, no carbide can precipitate in both the lath martensite and retained austenite. 


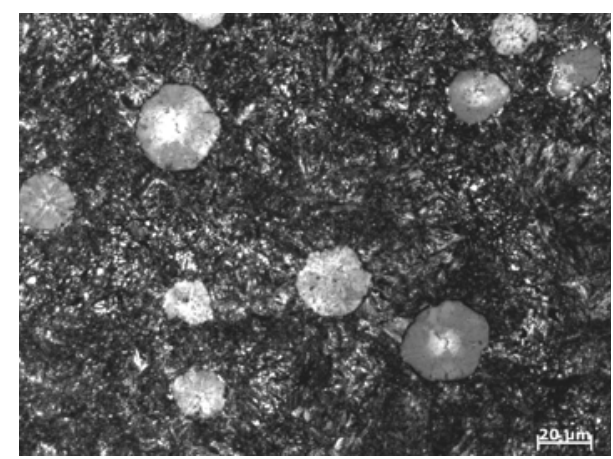

Figure 2. Microstructure of samples only quenched at $160^{\circ} \mathrm{C}$

After quenched at $160^{\circ} \mathrm{C}$, the samples are poured into nitrate furnace with $300^{\circ} \mathrm{C}$ to carry out partitioning process. The partitioning time keeps 10, 30, 60, 120, and 180 minutes, respectively. And their microstructures are observed by the optical microscope, as shown in Fig. 3 (a)-(e).

It is apparent that when the partitioning time is about 10 minutes, the lath martensite also can be found and the amount of martensite group decrease compared to the microstructure only quenched at $160^{\circ} \mathrm{C}$ (see Fig.2). Meanwhile, with the carbon atoms diffused from the lath martensite, the martensite with high carbon will transform into martensite with low carbon, which can make the tensile strength decrease and the cubic degree of martensite increase. Meanwhile, among the lath martensite or in the retained austenite, the fine and dispersive carbides can form, which is characteristic of tempering process of the matrix. This can increase the tensile strength and decrease the amount of the retained austenite. In addition, the carbon atoms in the lath martensite with high carbon will diffuse into the retained austenite and the retained austenite will have high carbon content, which can make the retained austenite stabilize. As a result, some retained austenite has been a steady presence at room temperature. Meanwhile, since the partitioning temperature is just in between the bainite transition temperature and the partitioning time is longer than the incubation time of lower bainite [18], the retained austenite can carry out isothermal quenching process and transform into the lower bainite. The amount of lower bainite is low because of short time of partitioning time, as indicated in Fig.3a.

With increasing the partitioning time to 30 minutes (Fig.3b), the lath martensite also can be found but the boundary between the lath martensite becomes blurred. Meanwhile, the fine and dispersive carbides increase, which form point distribution chain. In addition, some retained austenites with high carbon decompose into carbides; the other retained austenite will carry out an isothermal quenching process. The isothermal quenching process is mainly composed of two stages [19]:

$$
\gamma \rightarrow B+\gamma_{H C} \text { and } \gamma_{H C} \rightarrow B+\text { carbide }
$$

where, , B stand for the retained austenite, the austenite with high carbon content and the lower bainite, respectively. It is noted that the lower bainite is a kind of carbide-free bainite [15] and the lower bainite display the morphology of fine needle. With the partitioning time increasing further, these two stages will be long enough to fulfill, leading to the increase of the amounts of both the lower bainite and the carbides, as shown in Fig. $3 \mathrm{c}$ and d. Therefore, the mechanical properties can be great improved because of excellent properties of the lower bainitie. When the partitioning time prolongs further, the amount of the lower bainitie increase and the amount of lath martensite decrease. In addition, the retained austenite with high partitioned carbons can transform into martensite with high carbons when cooled to the room temperature [20]. Therefore, the final microstructures are composed of graphite nodules plus lath martensite plus retained austenite plus lower bainitie plus the carbides. 
Moreover, some graphite nodules has already lost regular sphere shape because of long partitioning time, as shown in Fig.3e, which can lead to the decrease of the mechanical properties.

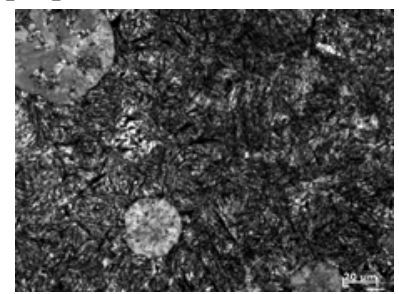

(a)

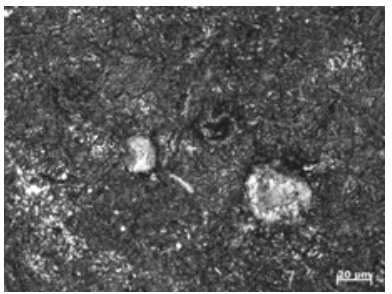

(b)

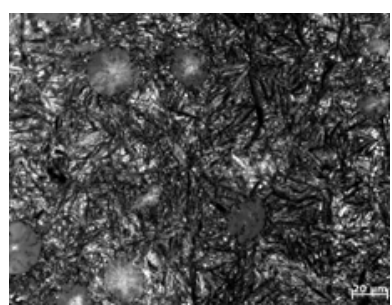

(c)

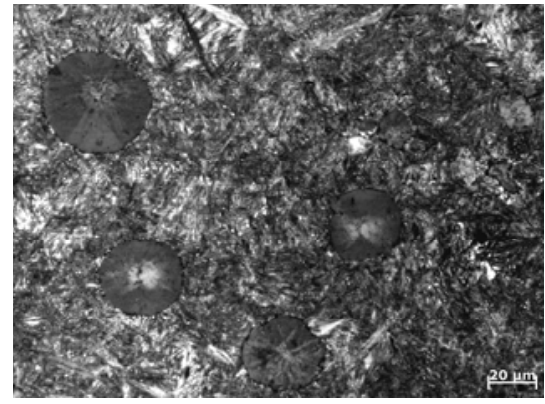

(d)

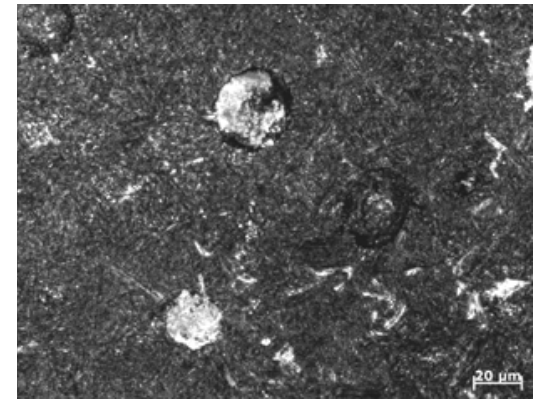

(e)

Figure 3. Microstructures under various partitioning times

(a) 10 minutes; (b) 30 minutes; (c) 60 minutes; (d) 120 minutes; (e) 180 minutes

As mentioned above, the partitioning process has a significant effect on the microstructures and then also can plays an important role in the mechanical properties of DCIs. Fig. 4 shows the changes of both tensile strength and elongation with the partitioning time. It is obvious that the as-cast sample has low tensile strength and high elongation, which can be ascribed to its matrix microstructure consisting of ferrite and pearlite.

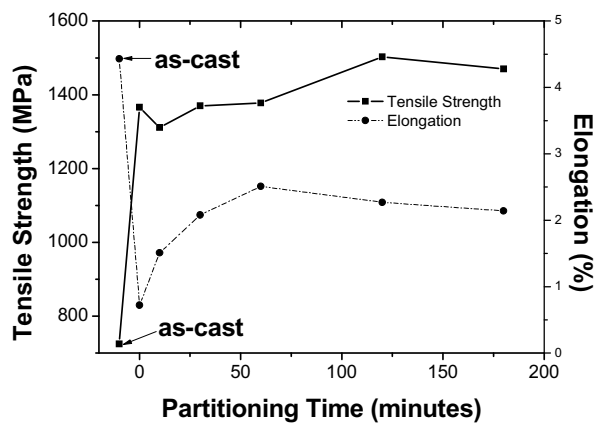

Figure 4. The curve of tensile strength and elongation with the partitioning time

After quenching and no partitioning, the sample has higher tensile strength and lower elongation than as-cast sample because of its lath martensite with dislocation tangles and interior stress. The observation also shows this sample displays the brittle fracture mode by cleavage, as shown in Fig.5(a). When the partitioning time is short, tempering process play a main role in phase transformation. Therefore, the tensile strength decrease and the elongation increase. 

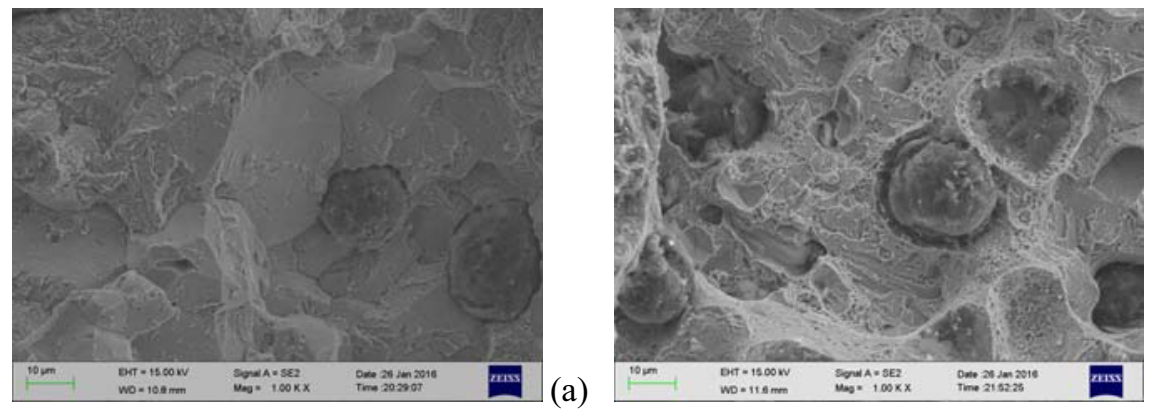

Figure 5. Fracture surface of samples (a) the quenched samples, (b) the samples partitioned for 120 minutes

When the partitioning time is short, tempering process plays a main role in phase transformation. Thus, the tensile strength decreases and the elongation increases. And the fracture surface shows ductile-brittle mode. With increasing the partitioning time further, both the carbides precipitated in martensite and the retained austenite having high carbon diffused from martensite will lead to the decrease of carbon content in martensite and then the decrease of tensile strength. Meanwhile, the retained austenite can exist steadily because of high carbon content. They can not be decomposed and can transform into the lower bainite. The lower bainite has good matching of tensile strength and elongation, giving rise to the fact that both the tensile strength and elongation increase, which can be confirmed by the fracture surface, as shown in Fig.5 (b). It is clear that this sample displays the ductile fracture mode having lots of dimples. With the partitioning time increasing further, the retained austenite with supersaturated carbon will decompose into carbides, which decrease the tensile strength and elongation.

\section{Conclusions}

In this work, the quenching and partitioning heat treatment was applied to the ductile cast irons and the effect of the partitioning time on the microstructure and mechanical properties were investigated in details. Lastly, the conclusions were obtained as follows:

1) The as-cast sample contains both the graphite nodules rated for 3 grade of nodulization and the matrix consisting of about $26 \%$ ferrite and $74 \%$ pearlite, which has low tensile strength and high elongation.

2) The sample with quenching and no partitioning had high tensile strength and low elongation because of its lath martensite with dislocation tangles and interior stress, confirmed by the brittle fracture mode of this sample.

3) With the partitioning time increasing, there were two processes to carry out, both of which affected the microstructures of DCIs. The final microstructure was composed of graphite nodules plus lath martensite plus retained austenite plus lower bainitie plus the carbides. Meanwhile, both the tensile strength and the elongation first increased and then decreased with the partitioning time, reaching a maximum at certain partitioning time, which can also be explained by the change of the fracture mode from brittle to ductilebrittle.

\section{Acknowledgment}

This work was supported by the Natural Science Foundation of Shandong Province of China (No. ZR2012EMM007) and a student innovation fund (No. SF2014006). In addition, the authors were grateful to Prof. Yonghua Rong and Prof. T. Y. Hsu (Zuyao Xu, 
Academician of the Chinese Academy of Sciences) of Shanghai Jiaotong University for their beneficial helps.

\section{References}

1. A. Basso, M. Caldera and J. Massone. ISIJ International 55 (2015) 1106-1113.

2. $\quad$ P. H. S. Cardoso, C. L. Israel, T. R. Strohaecker. Wear 313 (2014) 29-33.

3. C. F. Han, Q. Q. Wang, Y. F. Sun and J. Li. Metallogr. Microstruct. Anal. 4 (2015) 298-304.

4. T. Sun, R. B. Song, F. Q. Yang, and C. J. Wu. Metallurgy and Materials 21 (2014) 871-877.

5. P. Canzar, Z. Tonkovic, and J. Kodvanj. Mater. Sci. Eng. A 556 (2012) 88-99.

6. $\quad$ N. S. Tiedje. Mater. Sci. Tech. 26 (2010) 505-514.

7. J. M. Borrajo, R. A. Martinez, R. E. Boeri, and J. A. Sikora. ISIJ. Int. 42 (2002) 257263.

8. R. A. Gonzaga. Mater. Sci. Eng. A 567 (2013) 1-8.

9. Q. C. Li, G. W. Chang, R. X. Li, X. R. Chen, Q. J. Zhai. Transactions of Materials and Heat Treatment (In chinese) 29 (2008) 118-121.

10. R. Kumar, R. K. Behera, S. Sen. IOP Conf. Series: Mater. Sci. Eng. 75 (2015)1-8.

11. M. Soliman, H. Ibrahim, A. Nofal, H. Palkowski. J. Mater. Process Tech. 227 (2016) $1-10$.

12. A. W. Filho, B. V. Souza, C. A. Santos. Mater. Manuf. Process 30 (2015)1317-1323.

13. J. W. Zhang, N. Zhang, M. T. Zhang, L. T. Lu, D. F. Zeng. Mater. Lett. 119 (2014)4750 .

14. A. J. S. T. Silva, H. Goldenstein, W. L. Guesser, M. F. Campos. Mater. Res. 17 (2014) 1115-1123.

15. J. G. Speer, D. K. Matlock, B. C. De Cooman, J. G. Schroth. Acta Materialia 51 (2003)2611-2622.

16. ASTM A247. Annual book of ASTM Standards, American Society for Testing Materials, 1990.

17. A. J. Clarke, J. G. Speer, M. K. Miller, R. E. Hackenberg, D. V. Edmonds, D. K. Matlock, F. C. Rizzo, K. D. Clarke, E. D. Moor. Acta Materilalia, 56 (2008)16-22.

18. A. W. Filho, B. V. De Souza, and C. A. Dos Santos. Mater. Manuf. Process 30 (2015)1317-1323

19. Z. S. Xu. Hot Working Technology (In chinese) 6 (1998) 33-35.

20. J. H. Li, D. C. Lin. Metallographic Atlas of metallic materials. China Machine Press, 2006. 